\title{
RELIABILITY ANALYSIS OF SLOPE STABILITY IN EARTHEN DAMS FOLLOWING RAPID DRAWDOWN
}

\author{
ZAKARIAE KAHOT ${ }^{1, *}$, RACHID DKIOUAK ${ }^{1}$, ABDELLATIF KHAMLICHI ${ }^{2}$ \\ ${ }^{1}$ Department of Physics, Mechanical and Civil Engineering Laboratory, Faculty of Sciences and Technology, \\ University Abdelmalek Essaadi, Tangier, Morocco \\ ${ }^{2}$ Department STIC, Communication Systems and Detection Laboratory, National School of Applied Sciences, \\ University Abdelmalek Essaadi, Tetouan, Morocco \\ *E-mail: zkahot08@gmail.com
}

\begin{abstract}
This work was dedicated to assessing reliability of slope stability in earthen dams following rapid drawdown. Modeling of the problem physics was based on saturated-unsaturated seepage flow through the nonlinear Richards equation, under the assumption of two-dimensional approximation in steady state and transient state. The modeling of seepage taking place inside the earth dam infill materials included soil parameters, the negative pore water pressure-hydraulic conductivity relationship as well as the negative pore water pressure-volumetric water content. Slope stability was analyzed by using safety factor as evaluated by the Bishop's simplified method. Solution of the governing equations in terms of pore water pressure and fluid flow velocity was performed by using the modules SEEP/W and SLOPE/W of the Finite Element based software package GeoStudio. The drawdown phenomenon was then analyzed and its influence on dam stability assessed by using surface response method and Monte Carlo simulation. A design formula was proposed in order to bound the probability of failure associated to slope stability.
\end{abstract}

Keywords: unsaturated-saturated soil, earthen dam, Richards equation, slope stability, reliability

\section{Introduction}

Groundwater seepage related problems are of major practical interest for geotechnical and geo-environmental engineering. Failure of earthen dams happens frequently due to water seepage flow through the porous infill materials. Failure can take various forms such as internal erosion or piping, foundation defects and slope instability. Earthen dams may work fine for many years, but they require suitable design and maintenance. They fail quickly if they are exposed to an event able to make them collapse. Rapid drawdown is known to be a dangerous condition under which stability of the upstream face can be critical. Therefore, slope stability of embankment faces is to be ensured during all circumstances of dam's existence. This kind of instability has been experienced in the past such as in the San Luis dam, California, following ordinary water withdrawal from the reservoir in September 1981.

Groundwater seepage has been the subject of many studies. Lemacha et al. [1] used the nonlinear Richards's equation which deals with saturated-unsaturated flows through porous media and solved the flow problem by means of a numerical iterative procedure based on the alternate directions implicit finite difference method. Botos [2] carried out a research to determine seepage characteristics for different exploitation strategies of water reservoirs. He has depicted, in view of that, the saturated area pattern when the maximum water level is maintained constant for a long period of time. Mao et al. [3] investigated the inverse modeling of flow through variably saturated media. They have given the necessary conditions for this problem to be well defined in terms of the existence of a unique solution in both homogeneous and heterogeneous porous media.

Andreaa [4] presented the seepage and stability analysis performed in unsaturated regime through Maneciu dam in Romania. He considered seepage analysis for both steady state and transient state. He used water infiltration as given by soil-water characteristic curve of the van Genuchten model [5]. Pore water pressure load, ground water level, path and quantity of flow were determined. Tan et al. [6] considered spatial variability of hydraulic parameters on the seepage flow analysis in earthen dams. The saturated-unsaturated seepage flow was numerically calculated by

This is an open-access article distributed under the terms of the Creative Commons Attribution-NonCommercial 4.0 International License (https://creativecommons.org/licenses/by-nc/4.0/), which permits unrestricted use, distribution, and reproduction in any medium for non-commercial purposes, provided the original author and source are credited, a link to the CC License is provided, and changes - if any - are indicated. 
combining Monte-Carlo simulation with random field theory. The authors concluded that neglecting spatial variability of hydraulic parameters leads to an overestimation of flow rate variation coefficient, which can yield then conservative design of these structures.

Wang et al. [7] presented a large scale experiment which was designed and conducted to identify premonitory factors that may be used in failure prediction for earthen dams. Surface deformation, dam seepage water turbidity and self-potential across the dam were selected as the target parameters. Athani et al. [8] presented a seepage and stability analysis using the finite element method. By using the parametric sensitivity analysis, the seepage and stability studies have revealed how important it is to consider the coupled effects on the stability issue of earthen dam. They concluded that the coupled analysis is a prerequisite for the design and performance evaluation of the earthen dam under all conditions of seepage and stability. The variation in friction angle was found to be important and affects largely the stability of the dam. However, coupling will not be considered in the present analysis in order to emphasize more straightforwardly the reliability of the limit state associated to slope stability of embankment faces.

Slope failure may happen in earthen dam even if it is designed with high safety factor because geomaterials are mostly dominated by uncertainties [9]. To incorporate this effect of uncertainties that are inherent to soil parameters in the problem of slope stability, reliability analysis of soil slope failure is considered in this work. This probabilistic issue has received considerable attention in various fields of sciences over the past decades and many reliability methods have been proposed in literature [10]. These include first-order reliability method (FORM), first-order second moment method (FOSM), second-order reliability method (SORM) and Monte Carlo simulation (MCS) [11]. Response Surface Methods (RSM) have also been used [12]. The RSM uses a computationally efficient representation to approximate more effectively the original physical model. This enables reliability analysis to be carried out explicitly based on the performance function corresponding to the RSM. Considering slope stability, many valuable works have been published in recent years, such as FOSM [13], MCS [14] and RSM [10], that were applied to assess reliability of slope stability design.

In this work, slope stability of upstream face of earthen dam following rapid drawdown of the reservoir is assessed through reliability analysis approach. The purpose is to analyze the saturated-unsaturated seepage flow taking place inside the dam infill materials and to characterize stability as predisposed by inherent uncertainties. Efficient system reliability analysis approach based on MCS and RSM methods is used to evaluate the probability of slope failure. Probabilistic modeling of the intrinsic variability of soil properties in terms of soil resistance parameters is made by lognormal distributions. These uncertainties are propagated then by seepage flow conditions and shear resistance in the infill materials of earthen dam to the actual factor of safety. The physical modeling employs the Richards equation that governs seepage in saturated and unsaturated porous media. The negative pore water pressure and hydraulic conductivity relationship as well as the negative pore water pressure and volumetric water content are considered through the van Genuchten model. For slope stability, the Bishop's simplified method is used. This method assumes horizontal interslice forces and satisfies vertical force equilibrium for each slice and moment equilibrium for the entire mass. Both steady state and transient state are simulated by using software packages GeoStudio SEEP/W and SLOPE/W [15]. A typical homogeneous earth dam is studied and reliability analysis is performed in view of uncertainties that may affect key parameters intervening in the slope stability problem.

\section{Materials and methods}

\subsection{Governing equations}

In the following, groundwater seepage is assumed to take place in a homogeneous and isotropic earthen dam. Water flows through the porous media filling the dam and the seepage pattern depends on soil composition, flow type, liquid properties and hydraulic gradient. Seepage is governed by Darcy equation in both saturated and unsaturated conditions. This equation expresses the fact that the volume rate of water flow per unit area is directly proportional to the rate of change of hydraulic head. Transient water flow taking place in soil under constant temperature can be modeled by applying mass conservation. The principle of mass conservation states that for a given control volume of soil, the rate of water exchange is conservative. Then, the net flux of inflow and outflow vanishes. Conservation of water mass in saturated-unsaturated porous media yields the so-called Richards equation [15], which writes under the following form

$$
\begin{aligned}
& \frac{\partial}{\partial x}\left(k_{x}\left(u_{w}\right) \frac{\partial H}{\partial x}\right)+\frac{\partial}{\partial y}\left(k_{y}\left(u_{w}\right) \frac{\partial H}{\partial y}\right)+Q \\
& \quad=m_{w}\left(u_{w}\right) \rho_{w} \frac{\partial H}{\partial t}
\end{aligned}
$$

where $x$ is the horizontal coordinate, $y$ the ascending vertical coordinate, $t$ time, $k_{x}$ and $k_{y}$ are the coefficients of permeability of the soil in the $x, y$ direction, respectively, $Q$ a source term, $\rho_{w}$ mass per unit volume 
of water, $m_{w}$ the slope of the soil-water characteristic curve called also water storage, $u_{w}$ the pore water pressure and $H$ the total head. head by

The pore water pressure is related to the total

$$
H=h+y,
$$

where $h$ is the pressure head defined as

$$
h=u_{w} /\left(\rho_{w} g\right)
$$

where $g$ is the gravity acceleration.

Considering the usual case where the term source is absent, to solve transient seepage associated with saturated-unsaturated soil, Eq. (1) requires soil properties in terms of coefficients of permeability and water storage. The hydraulic conductivity of the soil, as well as water storage, are functions of the negative pore water pressure $u_{w}$ in the unsaturated regions. This makes the Richards equation highly nonlinear and its numerical solution needs an appropriate iterative procedure. The relationships for negative pore water pressure (matric suction) - volumetric water content and negative pore water pressure - hydraulic conductivity are obtained experimentally for a given soil. The curve of negative pore water pressure - volumetric water content is known as the soil water characteristic curve. Generally, a decrease in volumetric water content leads to an increase in matric suction and a decrease in hydraulic conductivity. Conversely, an increase in volumetric water content leads to a decrease in matric suction and an increase in hydraulic conductivity. Note that for steady state seepage, only the coefficients of permeability are required because the time dependent term in Eq. (1) vanishes.

The soil volumetric water content $\theta$ is function of the pressure head $h$. It can be estimated as [16]

$$
\theta=\theta_{r}+\left(\theta_{s}-\theta_{r}\right)\left(\frac{1}{1+\alpha^{n} h^{n}}\right)^{1-1 / n},
$$

where $\theta_{s}$ is the saturated water content, $\theta_{r}$ the residual water content, $\alpha$ and $n>1$ are soil parameters.

The soil hydraulic conductivity along the $x$ or $y$ axis can be estimated by means of the van Genuchten model as [5]

$$
k=k_{s} \sqrt{\frac{\theta-\theta_{r}}{\theta_{s}-\theta_{r}}}\left\{1-\left[1-\left(\frac{\theta-\theta_{r}}{\theta_{s}-\theta_{r}}\right)^{\frac{n}{n-1}}\right]^{1-\frac{1}{n}}\right\}^{2},
$$

where $k_{s}$ is the saturated hydraulic conductivity.
To perform stability analysis of saturated-unsaturated soil, Fredlund et al. [17] formulated an extended Mohr-Coulomb criterion that describes the shear strength behavior as affected by matric suction. The failure envelope is a planar surface in the space of the stress state variables $\sigma-u_{a}$ and $u_{a}-u_{w}$, where $\sigma$ is the total stress and $u_{a}$ the pore air pressure which can be assumed to be equal to the atmospheric pressure. Shear stress at failure is given by

$$
\tau_{f}=c+\left(\sigma-u_{a}\right)_{f} \tan \varphi+\left(u_{a}-u_{w}\right)_{f} \tan \varphi_{b},
$$

where $\tau_{f}$ is the shear stress at failure, $c$ is the cohesion at zero matric suction and zero net normal stress, $\left(\sigma-u_{a}\right)_{f}$ is the net normal stress on the failure plane at failure, $\varphi$ is the internal friction angle related to the net normal stress variable, $\left(u_{a}-u_{w}\right)_{f}$ is the matric suction at failure, and $\varphi_{b}$ is an internal friction angle associated with matric suction and which describes the rate of increase in shear strength due to the action of matric suction. In general, $\varphi_{b}<\varphi$ is verified.

The global safety factor is calculated as the ratio of resisting forces to driving forces according to the Bishop method [18]. This procedure is based on the assumption that the interslice forces are horizontal [19]. A circular slip surface is also adopted in the simplified Bishop method. It has been found that the Bishop method yields factors of safety which are higher than those obtained by using the ordinary method of slices. Analyses that were performed by means of more refined methods which involve the forces acting on the sides of slices have shown that the factors of safety obtained by the simplified Bishop method are very close to the exact ones.

In the simplified Bishop method, the forces acting in the vertical direction of a slice are integrated. The resulting vertical forces are considered along with the Mohr-Coulomb criterion to determine the shear forces acting on the base of slices. Then, moments about the center of the circular slip surface are summed. The factor of safety is finally obtained as:

$$
S F=\frac{\sum_{j} \tau_{f} l_{j} R_{j}}{\sum_{j} T_{j} R_{j}},
$$

where $j$ is the slice index, $R_{j}$ the moment arm, $l_{j}$ the length of the slice bottom and $T_{j}$ the actual shear force acting on the circular slip surface.

The number of slices should be determined in order to get the least factor of safety. Using 30 slices may be found to be enough in certain cases. But, more slices can be considered in order to obtain a more refined evaluation of the factor of safety. Various circular slip surfaces should be considered in order to find 
the lowest value associated to the critical slip surface among all the possible failure surfaces.

The factor of safety should be assessed in terms of probabilities. Current codes [20] specify that the safety factor of slope stability against sliding for earth-fill dams should exceed 1.5 for heights below $200 \mathrm{~m}$. The corresponding target failure probability is then lesser than $1.33 \times 10^{-5}$. This safety factor is increased for earth-fill dams above $200 \mathrm{~m}$. It is suggested that target failure reliability should not exceed $5 \times 10^{-6}$ for heights up to $250 \mathrm{~m}$ and limited to $10^{-6}$ for dams heights above $250 \mathrm{~m}$

\subsection{Numerical simulation}

Different methods have been developed to solve seepage and stability problems as described by the nonlinear Eqs (1) to (7). These methods can be classified as analytical, experimental or numerical. In this work, use is made of the finite element software GeoStudio through its modules SEEP/W and SLOPE/W. GeoStudio is a package of software modules that can be used to evaluate the performance of dams and levees with increasing levels of complexity. These enable analysis of seepage, settlement, filling/draining, and stability performance. Simulation can be related to various scenarios taken during the entire construction sequence or during the exploitation period of the structure. Both long-term steady state and detailed transient analyses can be performed. Pore water pressures and stresses can be considered in slope stability analysis. The effects of earthquake loading, ground freezing/thawing or other land-climate interactions on the response of the structure can also be investigated.

In SEEP/W, the governing equations along with initial and boundary conditions are solved by using the finite element method through the Galerkin-weighed residual formulation [21]. SEEP/W allows considering various types of analyses ranging from simple saturated steady-state problems to sophisticated saturated/unsaturated time-dependent problems. The finite element solution for a transient analysis depends on time as indicated by Eq. (1). SEEP/W uses the backward difference method for time integration and uses Gaussian numerical integration to evaluate the element integrals. When the mass matrix is evaluated, a lumped formulation is used in SEEP/W to concentrate the off-diagonal coefficients of the mass matrix into the diagonal terms. The lumped formulation, with eventually diagonal scaling, is recognized to enhance numerical stability in transient analysis. For each integration point, SEEP/W evaluates the parameter $m_{w}$ from the volumetric water content function. In most cases $m_{w}$ is computed from the slope of a straight line between the old and new pore water pressures at the considered Gauss point.
The essential information required for seepage simulation under SEEP/W includes the description of the flow regime, the definition of spatial dimensions of the considered soil domain and the setting of the external boundary conditions. Material parameters in terms of the negative pore water pressure-volumetric water content and negative pore water pressure-hydraulic conductivity have to be supplied as data entries. Laboratory or in-situ permeability tests can be used to obtain them directly. However, if the infill soil types are known, typical moisture retention curves and permeability functions can be used for estimating these materials parameters.

One of the most important advantages of the developed saturated-unsaturated model is that the phreatic surface appears to be a particular isobar in the pressure head field with its value equal to the atmospheric pressure, [22]. It is then just a component of the whole hydraulic head field that controls more generally seepage of water in both the saturated and unsaturated zones. This is very important from a numerical point of view as, when solving seepage problems using the saturated-unsaturated formulation, no assumption is required regarding the phreatic surface and obvious external soil boundaries are enough for the analysis.

In the following, to analyze the upstream slope during drawdown of earthen dam, simulation is performed by means of GeoStudio SLOPE/W. This tool which is integrated into GeoStudio suite software enables to compute the safety factor of earth and rock slopes. SLOPE/W can effectively analyze complex problems for a variety of slip surface shapes, pore water pressure conditions, soil properties, analysis methods and loading conditions. Here SLOPE/W is used to analyse slope stability according to the generalized Mohr-Coulomb criterion as given in Eq. (6). Use is made of the simplified Bishop method given in Eq. (7).

\subsection{Reliability analysis}

Probabilistic analysis is performed with respect to a given limit state. In the actual work, the limit state is associated to the point where the safety factor is equal to a critical value indicating that the slope is just about to fail.

According to Eq. (7), failure occurs when

$$
g(X)=S F(X)-S F_{c} \leq 0,
$$

where $S F$ is the safety factor as defined in Eq. (7), $S F_{c}$ the critical safety factor fixed in design, $X$ is a vector containing all the variables that are considered in the reliability analysis and $g$ is the limit state function, called also the performance function. This defines a 
surface in the space of design variables which separates the acceptable region from that corresponding to failure.

Even if the infill soil is assumed to be homogenous and isotropic, the list of variables that are expected to have some influence on the factor of safety is too large. It includes the geometrical dimensions of the dam, the height of reservoir, the level of reservoir bottom and the saturated-unsaturated soil parameters: $c, \varphi, \varphi_{b}, \theta_{s}, \theta_{r}, \alpha, n, k_{s}, \gamma_{d}, G s, \gamma_{w}$, where $\gamma_{d}$ is the soil dry unit weight, Gs the soil specific gravity and $\gamma_{w}=\rho_{w} g$ the weight per unit volume of water.

The performance function $g(X)$ is not given explicitly. Coupling finite element software with a reliability code is a method that can be used to perform reliability analysis. However, this process is costly because frequent calls to the finite element code are needed in order to evaluate the actual performance function and its gradients. Furthermore, this approach may fail to converge due to lack of robustness. To overcome these difficulties, there exist various methods enabling to approximate the performance function when it is implicit. These yield simplified explicit mathematical representations of the exact limit state as their evaluation in terms of the basic random variables of the process become straightforward. The analytical model giving explicit representation of the limit state is constructed by performing pertinent trial of points over the explored domain of the basic design variables. This is generally performed according to a design of experiment table.

The most common approach to select a finite number of trial points uses a full factorial table that is generated by fixing three levels for each of the chosen factors. Using the obtained results from simulations performed for all of these particular points, a metamodel can be readily derived. It represents then an approximation of the state function over the entire domain used for this regression. RSM is a common method that can be used to derive an approximate model of the system [23]. The RSM is considered usually under the form of a polynomial function. Once this is achieved, defining the densities of probabilities that describe the intervening random variables permits to use the MCS reliability analysis to calculate the probability of failure associated to a design against the considered limit state.

Taking the set of 11 parameters that intervene in the present analysis to be random variables is not convenient as reliability analysis will be a cumbersome task; because the required number of datasets to derive approximate representation of the limit state will be unaffordable. So, an alternative strategy is implemented here in order to simplify the analysis by taking into account only the parameters that are expected to have significant influence on the factor of safety. The uncertainty affecting hydraulic conductivity is characterized by the uncertainty of the three parameters $\alpha, n$ and $k_{s}$; as $\theta_{s}$ and $\theta_{r}$ are easy to obtain and are then assumed to be not subjected to considerable uncertainties [24]. Furthermore, for clay or silty-clay infill parameter $n$ has very low standard deviation in comparison with that of $\alpha$ [25], so parameter $n$ will be supposed to be deterministic. The soil densities are also assumed to be less affected by material uncertainties and $\gamma_{d}, G s, \gamma_{w}$ are taken to be deterministic. So, by discarding the variability of the above mentioned parameters, assumed to be deterministic, from the actual reliability analysis, the vector of basic variables is given by

$$
X=\left[k_{s} \alpha c \varphi \varphi_{b}\right]^{\mathrm{T}} .
$$

Taking three levels for each factor a full factorial design of experiment table that includes a total number of combinations which is equal to $3^{5}=$ 243 can be constructed. Variations of these factors are fixed here for the particular case of silty-clay infill by taking medium values and lower and upper thresholds which are defined as the limits of rangers of parameters according to Table 2 . When all the combinations are simulated by using SEEP/W and SLOPE/W modules, the system response, which is here the factor of safety, can be evaluated. Polynomial regression can next be performed by using the Matlab command regstats and a RSM model is derived. The coefficient of determination $R^{2}$ should then be controlled.

At the final step of reliability analysis the MCS method is used. The principle of this method relies on a statistical simulation of the modelled system behavior. A sufficiently large set of random numbers is needed for that and it is required a suitable random number generator. Wang et al. [24] reported that the hydraulic parameters $\alpha$ and $k_{s}$ were lognormally distributed. In this work, the Matlab command lognrnd is used. This command relies on the Matlab random number generator rand which is based on the Marsaglia's random number generator algorithm [26]. After performing analysis of variance of the simulation results, the most significant intervening random variables are assumed to be independent and to be lognormally distributed. Each random variable is then defined by its mean and standard deviation. In practice, these distributions of probabilities are identified from experimental testing by performing standard statistics on the results obtained from a large number of samples. Fixing these densities of probabilities functions and the size of Monte Carlo population which is here $2 \times 10^{5}$, the probability of slope failure can be calculated for a given design target of safety factor. 


\section{Results and discussions}

In the following, steady state and transient seepage through an earthen dam which is supposed to be founded on an impervious ground soil are numerically analyzed by using SEEP/W. Seepage taking place in the dam infill according to Eq. (1) is assumed to be isotropic with $k_{y}=k_{x}$ and soil may be saturated or unsaturated.

\subsection{Geometric and material properties}

Let us consider the homogeneous earthen dam represented in Fig. 1. The width of the base is $50 \mathrm{~m}$, the crest height is $16 \mathrm{~m}$ and the width of the crest is $15 \mathrm{~m}$, the initial reservoir height is $H_{i}=11 \mathrm{~m}$.

The dam is made from infill material which is assumed to be silty-clay. Initial volumetric water content is fixed at $\theta_{s}=0.35$, residual water content is set at $\theta_{r}=0.05$, soil parameter $n=1.123$, while parameter $\alpha$ is variable. Figure 2 gives the curve for negative pore water pressure-volumetric water content for $\alpha=0.471 \mathrm{~m}^{-1}$ in the particular case of silty-clay soil. Figure 3 gives the van Genuchten curve for negative pore water pressure-hydraulic conductivity when $\alpha=$ $0.471 \mathrm{~m}^{-1}$ for the considered silty-clay soil.
One can notice that the volumetric water content and hydraulic conductivity undergo huge variations over the suction range $0-1000 \mathrm{kPa}$ on a logarithmic scale. The curve of silty-clay soil falls earlier than clay soil; this is due to the fact that this material has larger and uniform pore spaces, so the soil can begin draining freely at a low pressure.

For seepage analysis, the fixed material characteristics used in simulations are given in Table 1, while $\alpha$ is variable according to Table 2 .

For slope stability and analysis of variance, the considered levels of the intervening key factors are given in Table 2 .

Table 1. Mechanical and hydraulic characteristics of silty-clay

\begin{tabular}{lc}
\hline Parameter & Value \\
\hline Water unit weight $\gamma_{w}\left(\mathrm{kN} / \mathrm{m}^{3}\right)$ & 9.81 \\
Dry unit weight $\gamma_{d}\left(\mathrm{kN} / \mathrm{m}^{3}\right)$ & 16 \\
Specific gravity $G s$ & 2.65 \\
Saturated volumetric content $\theta_{s}$ & 0.35 \\
Residual volumetric content $\theta_{r}$ & 0.05 \\
Parameter $n$ & 1.123 \\
\hline
\end{tabular}

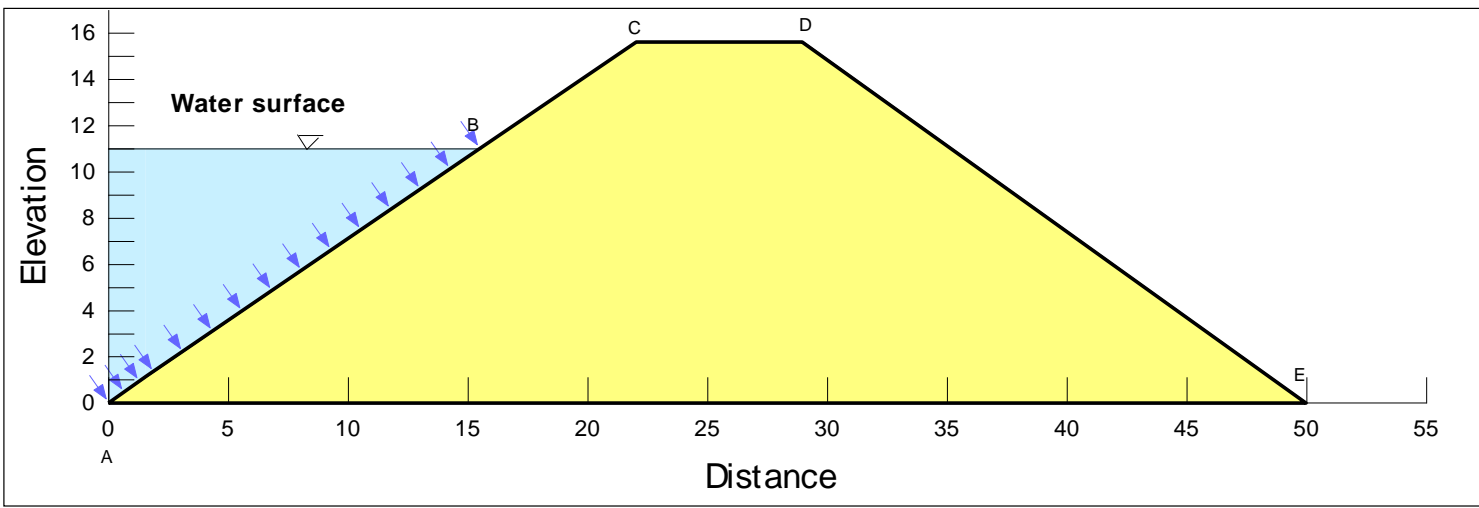

Fig. 1. Geometry of the considered earth dam

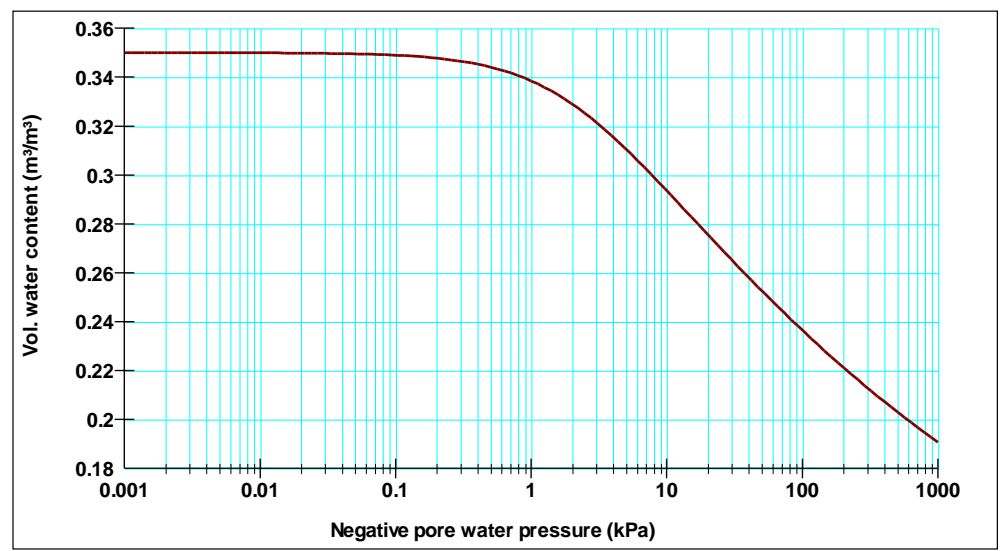

Fig. 2. Relationship for negative pore water pressure-volumetric water content $\alpha=0.471 \mathrm{~m}^{-1}$ 


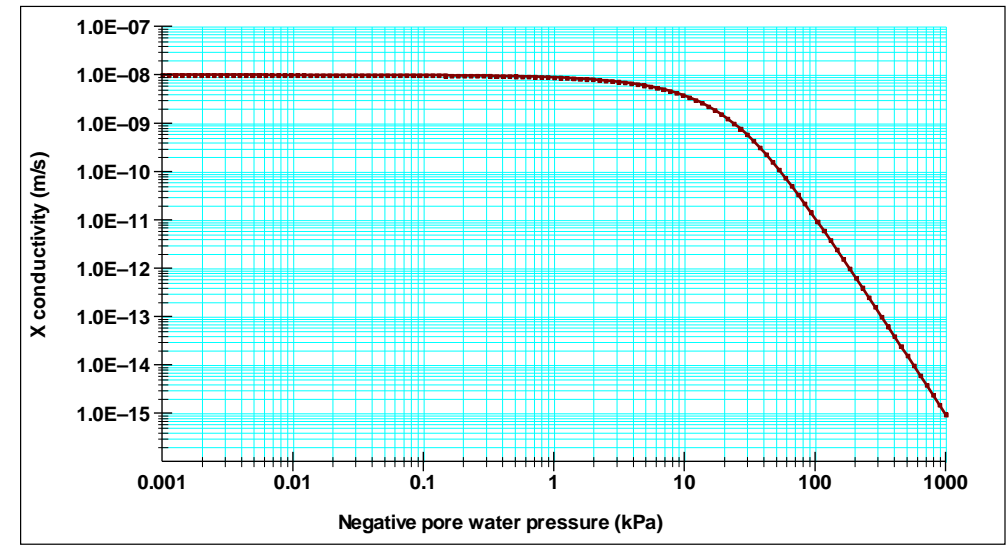

Fig. 3. Relationship for negative pore water pressure-hydraulic conductivity $\alpha=0.471 \mathrm{~m}^{-1}$

Table 2. Levels of the key factors considered in the analysis of variance for silty-clay

\begin{tabular}{lccc}
\hline $\begin{array}{l}\text { Random } \\
\text { variable }\end{array}$ & $\begin{array}{c}\text { Lower } \\
\text { threshold }\end{array}$ & Medium & $\begin{array}{c}\text { Higher } \\
\text { threshold }\end{array}$ \\
\hline$k_{s}(\mathrm{~m} / \mathrm{s})$ & $5 \times 10^{-9}$ & $10^{-8}$ & $5 \times 10^{-8}$ \\
$\alpha\left(\mathrm{m}^{-1}\right)$ & 0.319 & 0.471 & 0.641 \\
$c(\mathrm{kPa})$ & 30 & 35 & 40 \\
$\varphi\left({ }^{\circ}\right)$ & 18 & 25 & 32 \\
$\varphi_{b}\left(^{\circ}\right)$ & 14 & 16 & 18 \\
\hline
\end{tabular}

As only cohesion and internal friction coefficient will be found to be the only effective parameters explaining variability of safety factor against slope slip, the densities of probabilities functions of cohesion and internal friction angle that are used in reliability analysis are given in Table 3 . They are lognormally distributed and are given along with their means and standard deviations.

Table 3. Density of probabilities functions of the basic random variables for silty-clay

\begin{tabular}{lccc}
\hline $\begin{array}{l}\text { Random } \\
\text { variable }\end{array}$ & $\begin{array}{c}\text { Density of probabilities } \\
\text { function }\end{array}$ & Mean & $\begin{array}{c}\text { Standard } \\
\text { deviation }\end{array}$ \\
\hline$c$ & Lognormal & $35 \mathrm{kPa}$ & $7 \mathrm{kPa}$ \\
$\varphi$ & Lognormal & $25^{\circ}$ & $5^{\circ}$ \\
\hline
\end{tabular}

\subsection{Initial and boundary conditions}

Steady state analysis does not require initial conditions. The set of boundary conditions applied to the domain under analysis: pore water pressure and velocity distributions are in this case not time dependent. However, for transient analysis the initial conditions are required. As before considering transient state analysis, a steady state has previously been reached, initial conditions can be fixed by a steady state calculation performed prior to the transient anal- ysis. This step is considered in SEEP/W as the parent problem.

In the following, the dam is assumed to have reached steady state conditions with the reservoir water level fixed at $H_{i}=11 \mathrm{~m}$. During the transient process, the water level is assumed to decrease rapidly as function of time from this level to the reference value $H_{f}=0$, which corresponds to an unfilled reservoir. Time evolution of reservoir level is assumed to occur linearly during a given interval of time which is fixed by the drawdown procedure. This duration plays a major role in slope stability analysis as instantaneous or rapid drawdown may impact largely the stability of the dam upstream face. This is caused by the presence of a phreatic surface in the body of the embankment dam. When no water table is present in the reservoir, the direction of flow is reversed and the stabilizing effect due to high reservoir water level may be lost.

The boundary conditions correspond in the actual analysis to constant total head applied on the upstream face $A B$ with point $B$ variable in the case of transient analysis during drawdown. The default option of boundary conditions associated to vanishing flow holds for the other faces $B C D E$ and also for the impervious lower boundary of the dam $E A$ (see Fig. 1). For the steady state analysis or transient, the boundary conditions are given by

$$
\left\{\begin{array}{l}
H(x, y)=H_{i} \text { or } H(x, y, t)=H_{i}(t) \text { on } A B \\
k_{x}\left(u_{w}\right) \frac{\partial H}{\partial x} n_{x}+k_{y}\left(u_{w}\right) \frac{\partial H}{\partial x} n_{y}=0 \text { on } B C D E A
\end{array},\right.
$$

where $n_{x}$ and $n_{y}$ are the components of the external normal to the dam domain.

The second equation in system of Eqs (10), which corresponds to a vanishing flux at the associated face, is a natural boundary condition. It is taken into account automatically in SEEP/W through the finite element formulation. In SEEP/W, one has to declare also the downstream face in order to locate the part of that face which coincides with the atmospheric pressure isobar. 


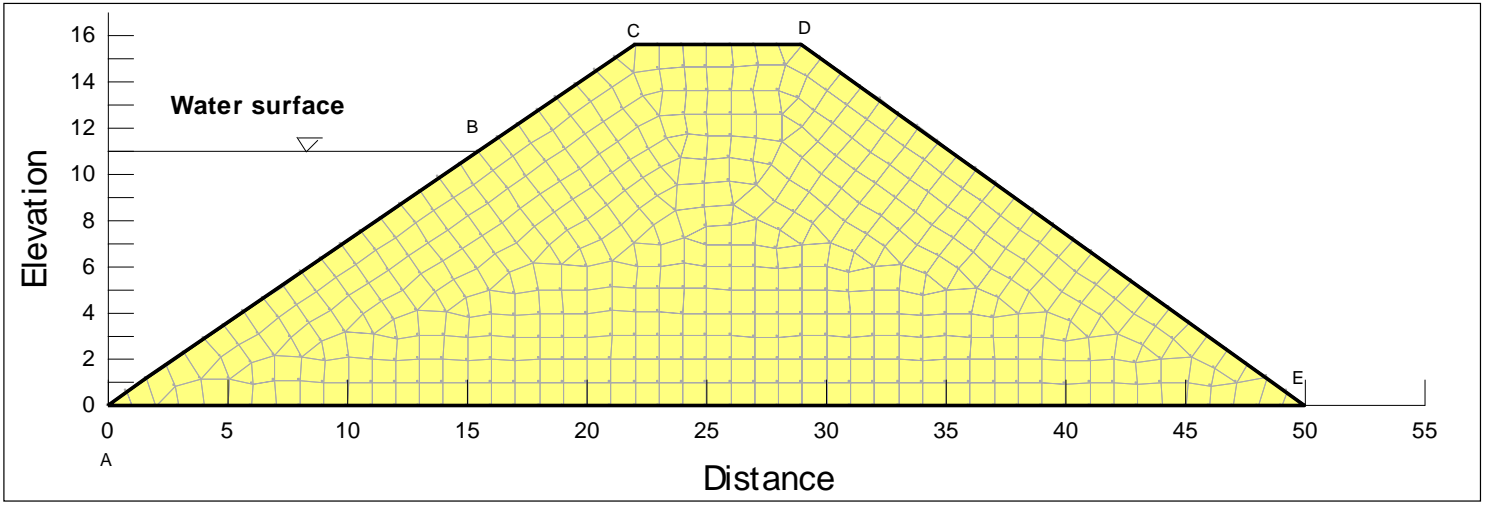

Fig. 4. Finite element mesh of the earth dam

This enables to assess more precisely the saturated part of that boundary as search for potential seepage face is turned on and an iterative method is activated.

\subsection{Finite element mesh}

The finite element mesh of the dam domain is considered here to be formed by triangular and quadratic elements. In simulations, mesh convergence was found to be reached for both steady state and transient state with the mesh size of $1 \mathrm{~m}$. Figure 4 gives the mesh used in simulations.

\subsection{Steady state analysis results}

Seepage problem as described by Eq. (1) and the data given above was simulated by means of SEEP/W. The boundary conditions are those given in Eq. (10).

Figure 5 gives the obtained flow path for siltyclay infill with $k_{s}=10^{-8} \mathrm{~m} / \mathrm{s}$ and $\alpha=0.471 \mathrm{~m}^{-1}$.

Figure 6 gives the obtained flow velocity field for silty-clay infill with $k_{s}=10^{-8} \mathrm{~m} / \mathrm{s}$ and $\alpha=0.471 \mathrm{~m}^{-1}$.

Figure 7 gives the obtained pore water pressure $u_{w}$ contours and values for silty-clay infill with $k_{s}=$ $10^{-8} \mathrm{~m} / \mathrm{s}$ and $\alpha=0.471 \mathrm{~m}^{-1}$.

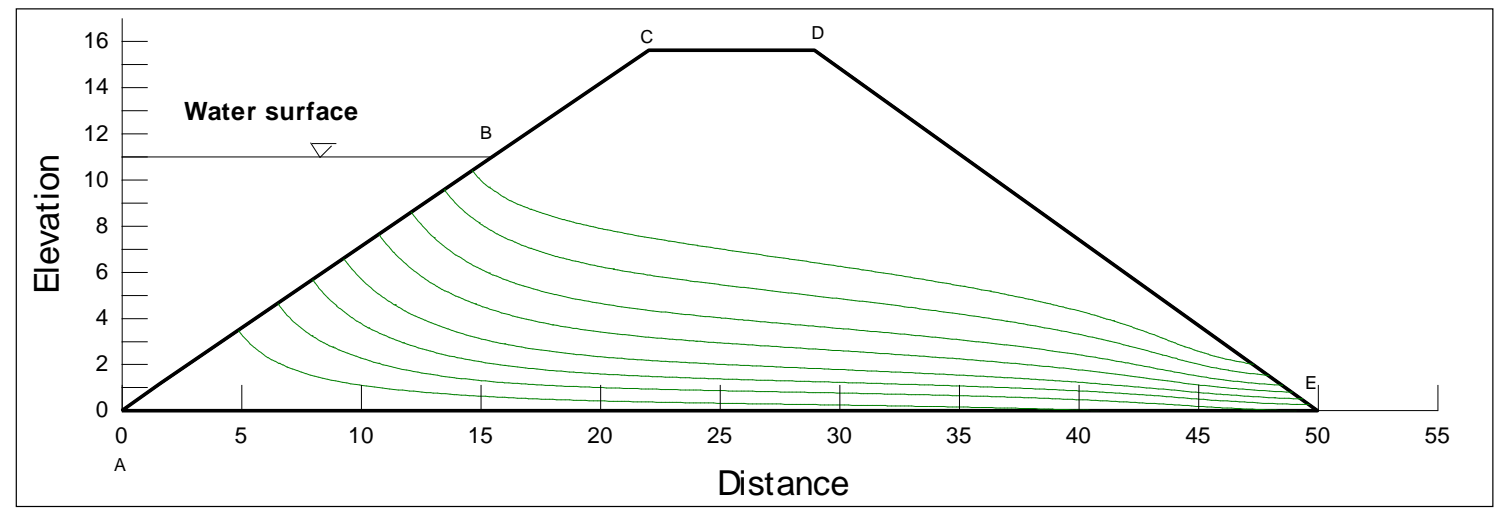

Fig. 5. Flow path in steady state; $k_{s}=10^{-8} \mathrm{~m} / \mathrm{s}$ and $\alpha=0.471 \mathrm{~m}^{-1}$

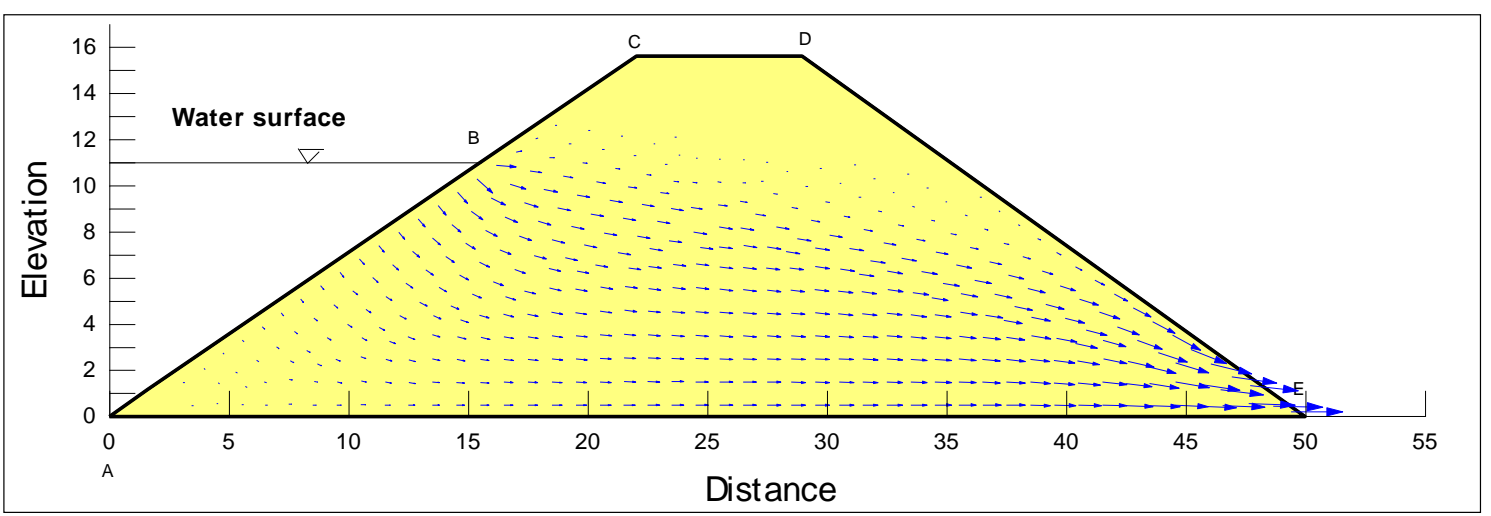

Fig. 6. Velocity vectors in steady state; $k_{s}=10^{-8} \mathrm{~m} / \mathrm{s}$ and $\alpha=0.471 \mathrm{~m}^{-1}$ 


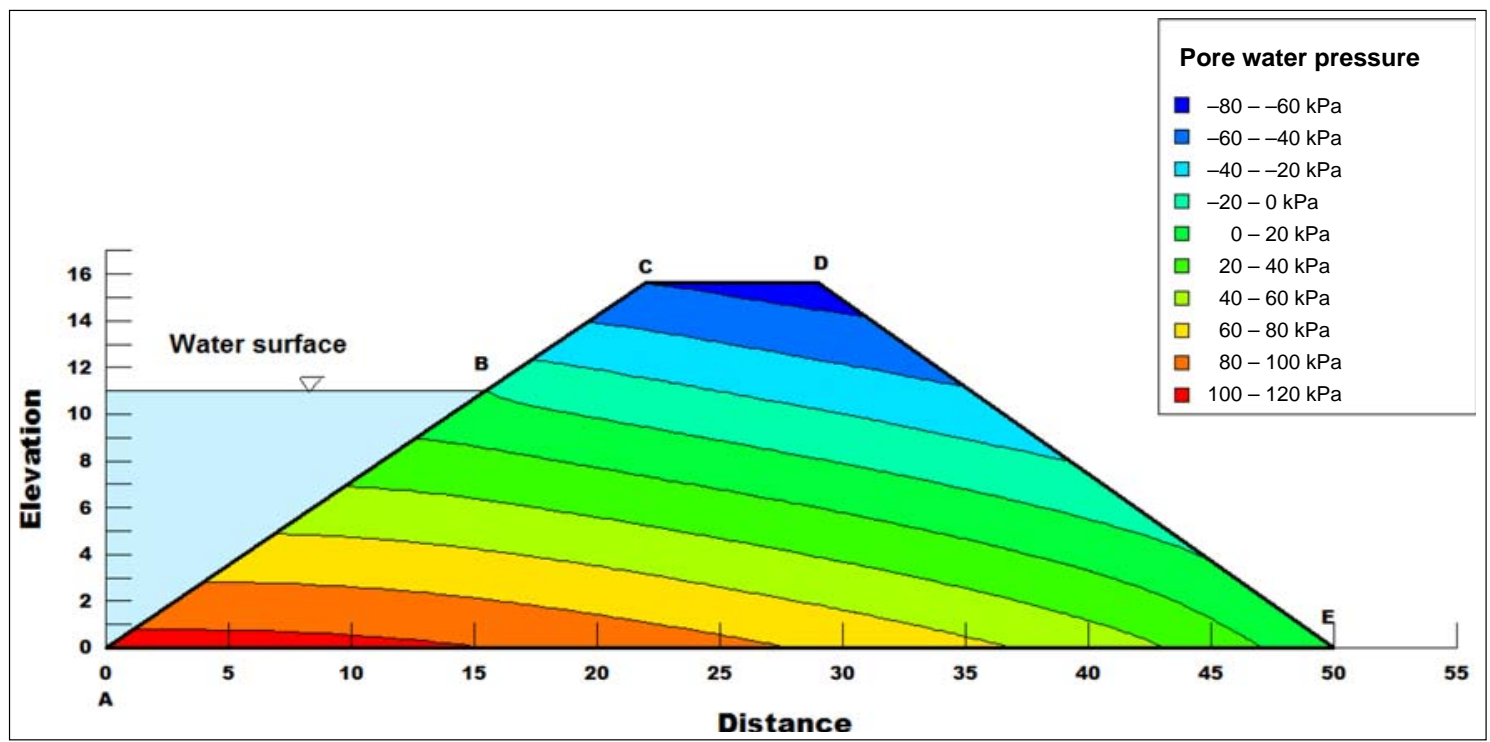

Fig. 7. Pore water pressure in steady state; $k_{s}=10^{-8} \mathrm{~m} / \mathrm{s}$ and $\alpha=0.471 \mathrm{~m}^{-1}$

Figure 5 shows that flow paths are starting from the reservoir and ending at the downstream face with higher density. Figure 6 shows that water velocity reaches its highest values at the bottom zone of the downstream face. This zone is critical for internal erosion and this is why a core is usually installed in earthen dams or at least a drainage zone preventing the flow paths from interesting the downstream face. Figure 7 shows that pore water pressure contours values exhibit the negative pore water pressure. This happens in the zone above the phreatic surface $u_{w}=0$ contour line. Figure 6 shows the existence of flow in this unsaturated zone.

\subsection{Transient analysis results}

One of the most important issues in dams servicing is to operate drawdown of the dam reservoir. If the reservoir is maintained at a high level during a long period of time, the fill material of the dam will then be fully saturated under the atmospheric pressure iso- bar and steady seepage will be well established. As the reservoir level draws down, pore water pressures in the dam body are reduced. This happens because there is a slower dissipation of pore pressure due to drainage occurring at the upstream face and because of the immediate elastic effect resulting from the removal of the total or partial water load. If the reservoir is drawn down rapidly, the direction of flow may be reversed and the stabilizing effect of high reservoir water level may be lost. This situation reflects a lower safety factor of the earth dam and may cause sliding of the upstream slope to occur.

To simulate drawdown process, the water level is assumed in the following to be drawn down rapidly from the initial reservoir level $H=16 \mathrm{~m}$ to the foundation level $H_{f}=0$ on the upstream side in 5 days. In addition to the boundary conditions given above in Eq. (10), one has to add the condition of downstream face on the actually upstream face $A B$ as potential seepage may occur there.

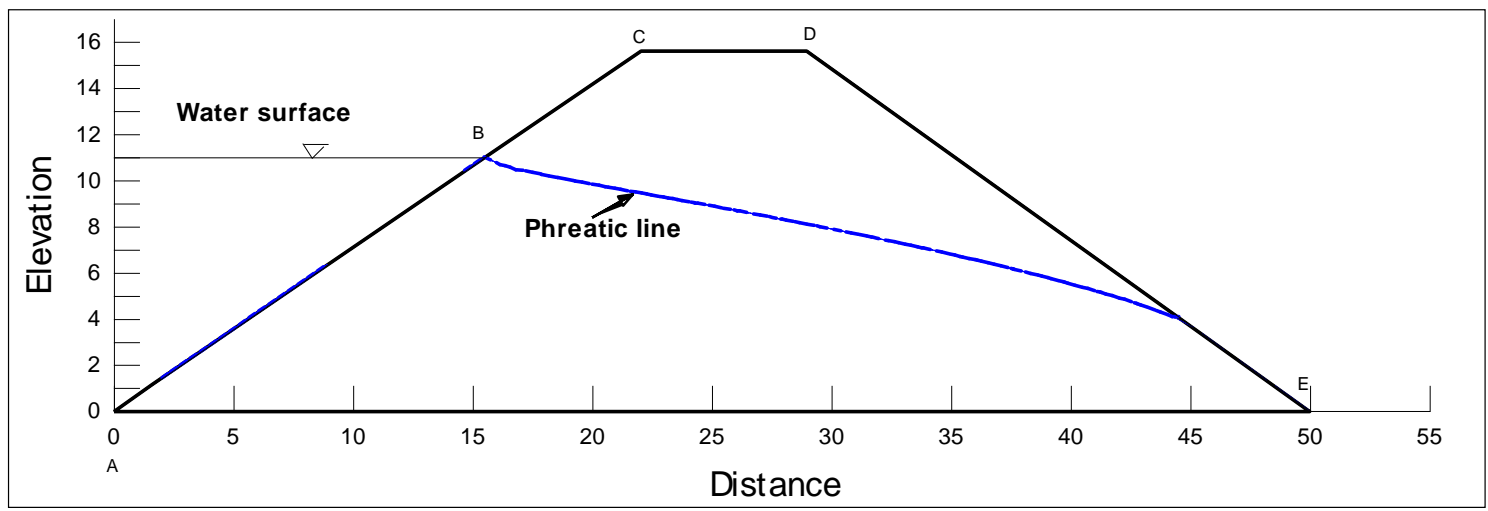

Fig. 8. Variation of the phreatic line for different times after rapid drawdown $k_{s}=10^{-8} \mathrm{~m} / \mathrm{s}$ and $\alpha=0.471 \mathrm{~m}^{-1}$ 
Figure 8 shows the variation of the phreatic lines at 0 until 5 days after rapid drawdown. The water starts to discharge from the upstream slope after drawdown.

\subsection{Earth dam's stability results}

Using SLOPE/W, slope stability analysis following rapid drawdown as simulated in the previous section is performed here. This is considered through the concept of reliability analysis where RSM and MCS are used. To derive a RSM for the slope stability limit state, each combination of the basic design variables $k_{s}, \alpha, c, \varphi, \varphi_{b}$, is simulated by first running SEEP/W to get the pore pressure results and then SLOPE/W to obtain the factor of safety $F S$ for this combination as function of time. Next, the minimum of this curve is determined.

Considering the combination of infill material properties defined by $k_{s}=10^{-8} \mathrm{~m} / \mathrm{s}, \alpha=0.471 \mathrm{~m}^{-1}$, $c=35 \mathrm{kPa}, \varphi=25^{\circ}$ and $\varphi_{b}=16^{\circ}$, Fig. 9 gives the sliding surface. The failure surface was divided into 30 slices as this was found to give asymptotic conver- gence in terms of safety factor. Figure 9 shows that the critical failure circle crosses the shear band.

Figure 10 gives the safety factor as function of the considered combination. Combinations are defined according to a full factorial design of experiment table with the increasing order of variations stated by the following sequence: $k_{s}, \alpha, c, \varphi, \varphi_{b}$.

The obtained maximum safety coefficient is 1.958, while the minimum safety coefficient is 1.294 .

Analysis of variance was performed on the obtained data in terms of the safety factor. The obtained results have shown that not all the parameters have the same influence on the safety factor. It was found that variability of results is due mainly to the coefficient of friction $(60 \%)$ and the cohesion $(40 \%)$. All the other factors and interactions represent only $0.08 \%$ which is quite marginal. This means that the factor of safety is only sensitive to variations of $c$ and $\varphi$ in the considered ranges of parameters as fixed in Table 2. This is in accord with the results obtained by Athani et al. [8], where they have stated that the variation in friction angle plays a vital role in the fulfillment of the stability criteria.

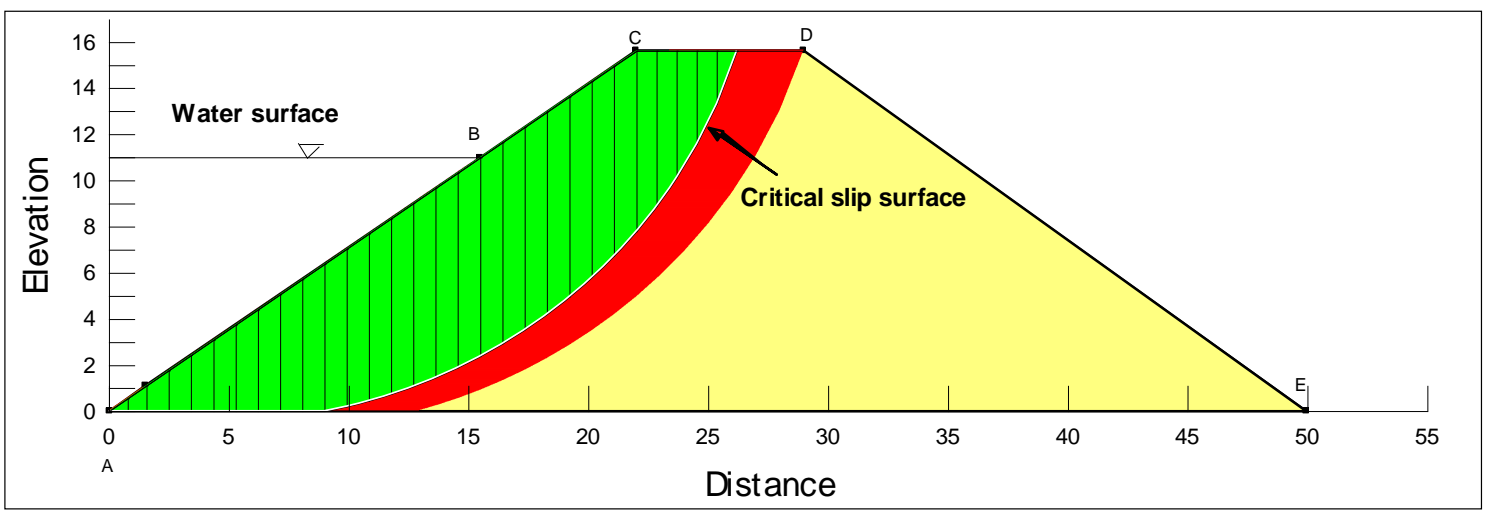

Fig. 9. Sliding surface passing through the shear band for silty-clay material properties: $k_{s}=10^{-8} \mathrm{~m} / \mathrm{s}, \alpha=0.471 \mathrm{~m}^{-1}$, $\mathrm{c}=35 \mathrm{kPa}, \varphi=25^{\circ}$ and $\varphi_{b}=16^{\circ}$

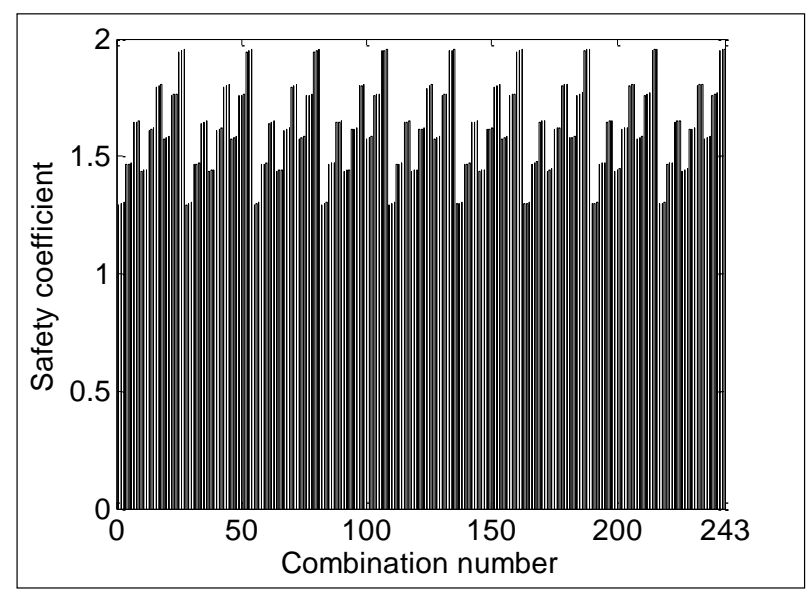

Fig. 10. Safety coefficient as function of the combination number of parameters: $k_{s}, \alpha, c, \varphi, \varphi_{b}$

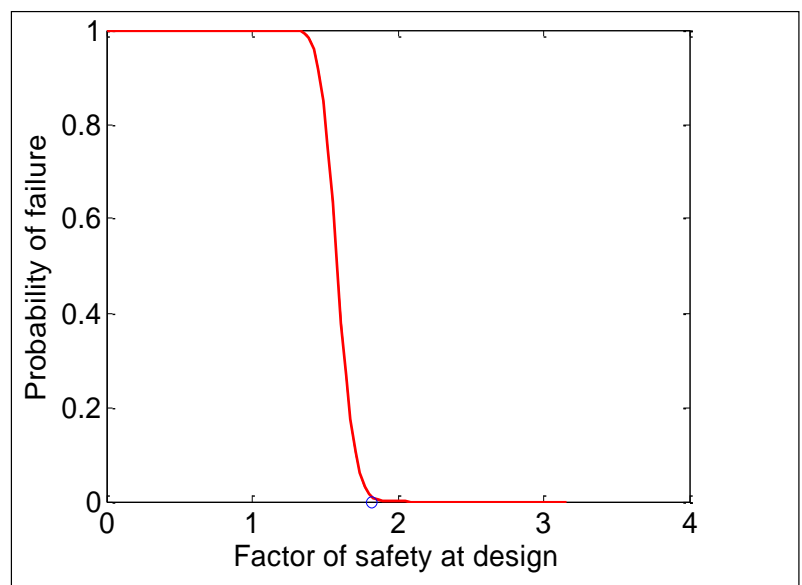

Fig. 11. Probability of failure as function of the factor of safety targeted in design 
Considering all the combinations of the basic design factors and the obtained results in terms of the most severe factor of safety, quadratic and linear polynomial regression in terms of these design variables were performed by using the Matlab command regstats. A high coefficient of determination $R^{2}>0.9999$ was obtained in both cases. This means that the RSM metamodel of the safety factor can be approximated by just a linear polynomial: $F S\left(k_{s}, \alpha, c, \varphi, \varphi_{b}\right)=F S(c, \varphi)$. Furthermore as only $c, \varphi$ are important, the obtained RSM took the pertinent form

$F S(c, \varphi)=-0.0845856+0.0293259 c+0.0257046 \varphi,(1)$

where $c$ is expressed in $\mathrm{kPa}$ and belongs to the interval $[30 \div 40] \mathrm{kPa}$, while $\varphi$ is expressed in degrees and belongs to the interval $[18 \div 32]^{\circ}$. For this correlation to be valid, the other parameters should remain in the corresponding intervals defined in Table 2.

Now, reliability analysis can be performed by using the limit state function defined by Eqs (8) and (11) and the random variables characteristics according to Table 3. Figure 11 gives the probability of failure as function of the value of safety factor targeted in design.

In Fig. 11, the blue circle is associated to a probability of failure which is equal to $1.33 \times 10^{-5}$. The associated factor of safety is equal to 1.823 . Note that the design with the medium values of Table 2 yielded a factor of safety which is equal to 1.616. This means that in terms of probability of failure this design is not safe enough. To obtain a design with the required probability of failure that remains less than $1.33 \times 10^{-5}$ one has to increase further performance of the material properties $c, \varphi$. This can be done by using the following correlation which guarantees always $F S \geq 1.823$ with a failure probability not exceeding $1.33 \times 10^{-5}$ :

$$
c \geq 65.05-0.8765 \varphi \text {. }
$$

This means in practice that energy of compaction should be adapted to reach the desired reliably value of $c$ when $\varphi$ is specified by a given infill material formulation.

\section{Conclusions}

This work focused on slope stability analysis of earthen dam following rapid drawdown. Use was made of seepage flow in saturated-unsaturated soils modeling by means of two-dimensional approximation of Richards's equation. Slope stability was investigated according to the generalized Mohr-Coulomb criterion that takes into account the effect of negative pore water pressure. These two steps were performed by using the modules SEEP/W and SLOPE/W of the finite element based software GeoStudio. Slope stability of silty-clay infill material was studied in terms of key factors including soil cohesion, internal friction coefficient, internal friction angle associated with negative pressure, hydraulic conductivity at saturation and the entering air parameter appearing in the van Genuchten equation describing saturated-unsaturated hydraulic conductivity. Considering the transient state associated to rapid drawdown of dam's reservoir, parametric results in terms of safety factor as estimated by the simplified Bishop approach were collected. This was performed according to a full factorial design of experiment table which was constructed on the basic design variables related to common silty-clay material properties by fixing three levels for each variable. Analysis of variance was performed after that on the obtained results. It was found that, in the investigated ranges of parameters, only the two factors: soil cohesion and internal friction coefficient explain variability of the safety factor. A linear regression model in terms of these two factors was shown to be highly accurate with the coefficient of determination greater than 0.9999. Using this response surface model representation of the safety factor, reliability analysis was conducted by means of Monte Carlo simulation where cohesion and internal friction coefficient were assumed to be lognormally distributed random variables. A design formula was then proposed in order to achieve probability of failure not exceeding $1.33 \times 10^{-5}$, which is retained in some codes like the Chinese for dams of height less than $200 \mathrm{~m}$. This formula can be further used to determine compaction needed to achieve the required level of cohesion when soil internal friction coefficient is estimated.

Seepage modeling used in this study has not considered porous-elastic coupling. It would be interesting to investigate the effect of this type of interaction on the dam stability. This can be achieved for instance by coupling the module SEEP/W with the module SIGMA/W of GeoStudio software. According to literature, coupling is expected to play a significant role in dam slope stability problem.

\section{References}

[1] Lemacha H., Maslouhi A., Razack M. (2017), Modeling of transient two dimensional flow in saturated-unsaturated porous media. European Scientific Journal, 13, 195-213.

[2] Botos M. L. (2014), Study of seepage for small homogeneous earth dams. Applied Numerical Mathematics and Scientific Computation, Proceedings of the 1st International Conference on Civil Engineering, Water Resources, Hydraulics \& Hydrology (CEWHH 2014), Atena, Greece, November 28-30, pp. 142-146.

[3] Mao D., Yeh T.-C. J., Wan L., Hsu K.-C., Lee C.-H., Wen J.-C. (2013), Necessary conditions for inverse modeling of 
flow through variably saturated porous media. Advances in Water Resources, 52, 50-61.

[4] Andreea C. (2016), Unsaturated slope stability and seepage analysis of a dam. Energy Procedia, 85, 93-98.

[5] van Genuchten M. T. (1980), A closed-form equation for predicting the hydraulic conductivity of unsaturated soils. Soil Science Society of America Journal, 44, 892-898.

[6] Tan X., Wang X., Khoshnevisan S., Hou X., Zha F. (2017), Seepage analysis of earth dams considering spatial variability of hydraulic parameters. Engineering Geology, 228, 260-269.

[7] Wang F., Dai Z., Okeke C. A. U., Mitani Y., Yang H. (2018), Experimental study to identify premonitory factors of landslide dam failures. Engineering Geology, 232, 123-134.

[8] Athani S. S., Shivamanth, Solanki C. H., Dodagoudar G. R. (2015), Seepage and stability analyses of earth dam using finite element method. Aquatic Procedia, 4, 876-883.

[9] Johari A., Lari A. M. (2016), System probabilistic model of rock slope stability considering correlated failure modes. Comput. Geotech., 81, 26-38.

[10] Li D. S., Zhenga D., Cao Z. J., Tang X. S., Phoon K. K. (2013), Response surface methods for slope reliability analysis: Review and comparison. Engineering Geology, 203, 3-14.

[11] Zhang J., Huang H. W., Juang C. H., Li D. Q. (2013), Extension of Hassan and Wolff method for system reliability analysis of soil slopes. Engineering Geology, 160, 81-88.

[12] Jiang S. H., Li D. Q., Cao Z. J., Zhou C. B., Phoon K. K. (2015), Efficient system reliability analysis of slope stability in spatially variable soils using Monte Carlo simulation. J. Geotech. Geoenviron., 141, 04014096.

[13] Low B. K. (2014), FORM, SORM, and spatial modeling in geotechnical engineering. Structural Safety, 49, 56-64.

[14] Wang Y. (2012), Uncertain parameter sensitivity in Monte Carlo simulation by sample reassembling. Comput. Geotech., 46, 39-47.
[15] GeoStudio. Headquartered in Calgary, Alberta, Canada. https://www.geoslope.com/

[16] Mualem Y. (1976), A new model for predicting the hydraulic conductivity of unsaturated porous media. Water Resour. Res., 12, 513-522.

[17] Fredlund D. G., Rahardjo H. (1993), Soil mechanics for unsaturated soils, John Wiley \& sons, Inc., New York, USA, pp. 38-63.

[18] Bishop A. W., Morgenstern N. (1960), Stability coefficients for earth slopes. Géotechnique, 10, 129-153.

[19] Spencer E. (1967), A method of analysis of the stability of embankments assuming parallel inter-slice forces. Géotechnique, 17, 11-26.

[20] Ma H., Chi F. (2016), Major technologies for safe construction of high earth-rockfill dams. Engineering, 2, 498509.

[21] Zienkiewicz O. C., Taylor R. L. (1967), The Finite Element Method; Volumes I, II, 5th Edition, McGraw Hill, New York.

[22] Freeze R. A. (1971), Three-dimensional, transient, saturated-unsaturated flow in a groundwater basin. Water Resour. Res., 7, 347-366.

[23] Gayton N., Bourinet J., Lemaire M. (2003), CQ2RS: A new statically approach to response surface method for reliability analysis. Journal of Structural Safety, 25, 99-121.

[24] Wang Y. Q., Shao M. A., Han X. W., Liu Z. P. (2015), Spatial variability of soil parameters of the van Genuchten model at a regional scale. Clean Air Water, 43, 271-278.

[25] Phoon K. K., Santoso A., Quek S. T. (2010), Probabilistic analysis of soil-water characteristic curves. J. Geotech. Geoenviron., 136, 445-455.

[26] Marsaglia G. (2013), XorShift RNG's. Journal of Statistical Software, 8, 1-6. 